REVISTA DE DERECHO UNED, NúM. 7, 2010

\title{
BOLONIA Y EL ARTE DE APRENDER
}

\author{
Francisco Eugenio DíaZ
}

UNED

Resumen: Primeramente se hace un mínimo repaso al historial universitario de Bolonia, que viene a comenzar en 1088. Después se hace una referencia al método educativo de la Institución Libre de Enseñanza, de la España de finales del siglo diecinueve y largo primer tercio del veinte, a la que perteneció el maestro Luzuriaga.

Más tarde se exponen, en paralelo, las tareas y valores -actitudes- de lo que se presenta como un Ars discendi propio. Seguidamente se ofrece una abreviada descripción de lo que significa el Espacio Europeo de Estudios Superiores, el llamado Plan Bolonia. Viene luego un apartado dedicado a Aprender haciendo: una serie de prácticas posibles, que van desde la elaboración de una Antología de textos hasta la preparación de un Vocabulario temático

Finalmente se exponen las conclusiones críticas sobre el denominado Plan Bolonia: 1, La capacitación profesional como objetivo prioritario; 2, La metodología de la enseñanza no es ajena a experiencias anteriores; 3 , Las nuevas herramientas de aprendizaje requieren nuevos adiestramientos; 4, Las actividades a realizar por el estudiante son pieza esencial en su propia formación; 5 , El dirigismo queda rebajado en algún caso con la declaración de cierta opcionalidad.

Palabras clave: Aprendizaje, Enseñanza, Plan Bolonia.

Abstract: First, we draw a short summing up focused on the Bologna university history since 1088. Later, there is a presentation of the education method developed by the Institución Libre de Enseñanza in Spain during the late XIXth century and first third of the XXth century, one of its members was the teacher Luzuriaga.

Secondly, we present in parallel the tasks and values -attitudes- of a specific Ars discendi. Next, there is a short description of the meaning 
of the European Higher Education Area, the so called Bologna Process, followed by a chapter on 'learning by doing: a set of possible practices' ranging from the creation of an anthology of texts to the formation of a glossary by issues

Finally, the critical conclusions on the so called Bologna Process are set down: 1, professional qualification as priority goal; 2 , the teaching methodology can not be severed from prior experiences; 3 , the new learning tools entail new training; 4, the activities to be done by the student are a essential part of his own training; 5 , the guidelines are balanced in some cases by some level of optional actions.

Key words: Bologna Process, Education, Learning.

Sumario: 1. Iniciación.-2. Bolonia en la memoria.-3. Un pasado reciente: Luzuriaga.-4. Ars discendi: dos quintetos en paralelo.-5. Triple E: Espacio Europeo de Estudios Superiores.-6. Aprender haciendo: una serie de prácticas posibles.-7. Conclusiones.-8. Bibliografía de referencia.

\section{1.- INICIACIÓN.}

Decía Laín que el universitario debe ser, entre otras cosas, un hombre de su tiempo. No se concibe ciertamente una persona -en general, y una persona de estudios en particular- desconectada del tiempo en el que vive. Nuestro tiempo, si nos atenemos a algunas de las palabras de más palpitante actualidad, es el tiempo de la globalización, de la sociedad del conocimiento, de las redes sociales, y, por lo que a las nuevas orientaciones del método de aprendizaje en las universidades se refiere, el tiempo del llamado Plan Bolonia.

En torno a este llamado Plan Bolonia nos proponemos hacer ahora algunas reflexiones: Bolonia y el arte de aprender.

Ante todo, y en atención a lo que el término Bolonia sugiere a los juristas, es preciso un mínimo repaso de lo que conlleva, en su historial universitario, el nombre de esta tan famosa ciudad italiana. Después, hemos de referirnos a un pasado reciente que, sin duda, viene a cuento: las ideas de Luzuriaga y su escuela sobre el método de aprender. Más tarde, en esa misma línea del arte de aprender, nos ocuparemos de lo que consideramos sus actuaciones y actitudes básicas, o sea, del Ars discendi. A continuación, vendrá la exposición y comentarios sobre el significado del Espacio Europeo de Estudios 
Superiores. Seguirá luego el apartado referido a Aprender haciendo: una serie de prácticas posibles, como propuesta acerca de las actividades que el estudiante, como artífice de su propia formación, podría llevar a cabo. Finalmente se indicarán las correspondientes Conclusiones.

\section{2.- BOLONIA EN LA MEMORIA.}

Bolonia, para un jurista, es la ciudad esencialmente vinculada al comienzo de los estudios del derecho, construido sobre la base del imperecedero derecho romano. Decir Bolonia, en el mundo jurídico, es decir I r $\mathbf{n}$ e r i o. Irnerio fue un gramático que tuvo que vérselas con un atractivo e inusitado texto, en 50 «libros», elaborado en tiempos de Justiniano, en el siglo VI, el Digesto: en esencia, una colección respuestas de juristas constitutiva de lo que se considera como el derecho jurisprudencial romano. Irnerio glosa, es decir comenta explicándolos, los pasajes del Digesto. Con Irnerio se funda, así queda admitido generalmente, la Universidad de Bolonia, se dice que en el 1088. Desempeñó Irnerio elevados cargos al servicio del emperador Enrique V, en el periodo de tiempo que va del $\mathbf{1 1 1 6}$ al 1118.

A Irnerio le siguieron, ya en la segunda mitad del siglo XII, los juristas recordados como los cuatro doctores; a saber: Búlgarus, Martino, Hugo y Jacobus. Búlgaro fue considerado por sus contemporáneos como el Crisóstomo -boca de oro-de la Jurisprudencia; boloñés, falleció en el año 1166. Martino fue considerado por los escritores antiguos como uno de los más sabios jurisconsultos de su época: su muerte fue anterior a la de Búlgaro. Hugo es coetáneo de los anteriores y, como ellos, boloñés: se dijo de él que era el espíritu de las leyes. Jacobo, llamado Jacobo de Porta Ravennate y, para distinguirlo de Jacobo Balduino (el maestro de Odofredo), llamado incluso Jacobus antiquus doctor, vivió hasta octubre de $\mathbf{1 1 7 1 .}$ Uno de los contemporáneos de Irnerio atribuyó al mismo el dístico que dice: Bulgarus est [os] aerum, / Martinus copia legum, // Mens legum est Hugo, / Jacobus id quod ego. [Búlgaro es boca de oro; / Martino es copia literal de las leyes; // Hugo es la intención de las leyes; / Jacobo es mi "alter ego»].

Otros juristas, tanto o más importantes que los anteriores, surgidos también en el ámbito de la escuela que se origina con Irnerio fueron: 
[1] Placentino (llamado así porque nació en Piacenza) , primeramente profesor de derecho en Bolonia y después fundador de la primera escuela de derecho que tuvo Francia (en Montpelier: allí murió en 1192). [2] Juan Basiano, que estudió bajo la dirección de Búlgaro. Los escritos que de este jurisconsulto se conservan son los siguientes: Glosas, una Suma a las Auténtica, un tratado de acciones y la Summa Quiqumque vult, (se trata de una sección particular de procedimientos, de los requisitos de la demanda). Juan Basiano fue preceptor de Azón; éste y Accursio aceptaron sus opiniones.[3] Vacario, que llevó de Bolonia a Inglaterra en 1144 manuscritos de los textos de Justiniano, y fundó en Oxford una escuela de derecho, propagación de la de Bolonia.

[4] A z ó n (el profesor del que se dice que sólo enfermaba en tiempo de vacaciones y que su cátedra era la más concurrida de Bolonia), cuya solvencia jurídica era tal que ha quedado recogida en el adagio de "Chi non ha Azo non vada a Palazzo», esto es, quien no conozca la obra jurídica de Azo no está en condiciones de defender pleito alguno; Azón vivió hasta el año 1230, por lo menos. [5] Jacobo Balduino, uno de los célebres discípulos de Azón, con Accursio; este ilustre jurisconsulto prestó en el año 1213 juramento de profesor en Bolonia, su patria; uno de sus discípulos fue Odofredo; murió Jacobo Balduino en el 1235.

[6] A c u r s i o, tenido como el jurisconsulto de más fama de entre todos los de la escuela de Bolonia, reconocido por su obra consistente en una vasta colección que hizo de las glosas de sus predecesores y contemporáneos, la cual viene conocida con el nombre de Glosa ordinaria o Glosa Magna. Acursio murió en Bolonia en el año 1260. Con Acursio se cierra la escuela de los glosadores. Como Irnerio había sido, en el ámbito del derecho, la autoridad del siglo XII, así fue Acursio la autoridad del siglo XIII, y así llegará a ser Bártolo la autoridad del siglo XIV.

Tras la escuela de los Glosadores viene, ya en siglo XIV , la escuela de los Comentaristas o postglosadores. Las más importantes figuras de postglosadores son Bártolo de Sassoferrato (que vive del 1314 al 1367) y su discípulo Baldo de Ubaldis (que muere ya en el 1400). Con los postglosadores la literatura jurídica se desvirtúa un tanto, pues se prefiere el estudio de la glosa al estudio de las originales fuentes. Con todo, para un romanista y civilista como Clemente de Diego, Bártolo ha significado en Derecho lo que Aristóteles en Filosofía. Bártolo fue profesor de derecho en Bolonia, Pisa y Perugia, donde murió en el 1357. Es oportuno traer aquí el dicho 
popular de «recoger los bártulos» que alude al hecho de que fueron los textos del comentarista Bártolo -los «bártolos»- textos de uso escolar que, tras su uso en las clases, había que recoger; hoy la expresión alude a recoger cualquier tipo de materiales de uso, de enseres que se manejan. De Baldo, que enseñó derecho en Bolonia, Perusa, Pisa y Padua, se dice que llevó hasta el límite los vicios de los comentaristas.

Por si fuera poco, el hecho de que Bolonia resulta inseparable de las escuelas de glosadores primero y postglosadores después, Bolonia ocupa un destacadísimo lugar en orden a la formación de juristas españoles: pues es la sede del Colegio Español de San Clemente, en Bolonia (el Colegio Español de Bolonia), institución fundada en 1364 para dar albergue a los estudiantes que frecuentaban la Universidad de Bolonia y dotada con los fondos que para este fin legó en su testamento el cardenal Carrillo de Albornoz (que fue nombrado cardenal por el Papa Clemente VI, en Avignon, en 1350). Esta institución sigue vigente en nuestros días y por ella han pasado generaciones y generaciones de eminentes juristas.

Hemos hecho una breve pero inevitable referencia a Bolonia, como la sede de estudios jurídicos que fue, y que sigue siendo, para rendir el tributo que merece tan señero nombre en la tradición de los estudios de derecho y, en general, de la tradición universitaria. Es preciso anotar también que en los proyectos de futuro hay generalmente un poso de experiencias acumuladas del pasado.

Quiere decirse que los principios del proyecto educativo llamado «Plan Bolonia» ya se habían puesto en práctica por antepasados nuestros: como la educación en las competencias profesionales (así, Juan Basiano primero y Rodofredo Epifanio después son ejemplo de un planteamiento del saber para el saber hacer, con su especial atención a las acciones utilizables en los procedimientos judiciales); como la planificación del aprendizaje (así, la distinción entre unas materias de aprendizaje necesario -las «ordinarias»-y otras materias de aprendizaje potestativo -las extraordinarias; la profundización en algunas cuestiones mediante las llamadas «repetitiones»; la previsión de sesiones prácticas; etc.); y como, sobre todo, el gusto por la consulta de los textos, de las originarias fuentes. Todo ello en perfecta sintonía con una enseñanza participativa, crítica y creativa, por bautizarla con la terminología actualmente en uso. 


\section{3.- UN PASADO RECIENTE: LUZURIAGA}

Lorenzo Luzuriaga (que nació en Valdepeñas en 1889 y murió en Tucumán en 1965) se formó en la Institución libre de enseñanza (institución pedagógica creada en España en 1876 por Francisco Giner de los Ríos y otros profesores liberales) y fundó en Madrid, en 1922, la «Revista de Pedagogía», que dirigió hasta su desaparición en 1936 y que constituye una obligada referencia en el ámbito educativo de entonces, que bien podemos calificar como nuestro pasado reciente.

En la colección «Publicaciones de la Revista de Pedagogía»se editó en 1927, $2^{\mathrm{a}}$ ed., renovada, un opúsculo de 48 páginas titulado»El programa escolar», cuyo autor es Fernando Sáinz (quien, como el propio Luzuriaga, también fue inspector de primera enseñanza). Nos servirá esta obrita para, al hilo de lo que en ella se dice, ofrecer algunas anotaciones, numeradas, que estimamos válidas en relación con los, supuestamente nuevos, métodos de enseñanza universitaria.

\subsection{La enseñanza, gimnasia mental.}

El punto de partida, aunque no se diga exactamente con estas palabras, viene a ser éste: qué hay que saber y por qué. Se empieza señalando (pags. 9 y 10) que Lo enciclopédico en la cultura [...] no es un poco de cada cosa, sino lo común a muchas cosas [...]; en suma, no es saber cosas, sino conseguir ideas madres, amplias, claves de innumerables ideas concretas. [...] La enseñanza, esencialmente, es una gimnasia de la inteligencia $y$, en consecuencia, el programa es, ante todo, un programa de disciplinas del espíritu. [...]Si la instrucción no se toma como sistema de disciplina del espíritu, sino como mero instrumento de aplicación a los usos de la vida, surge enseguida la consideración de la relativa importancia y preferencia de las materias [...].

Parece que, para nuestro autor, la enseñanza como «formación humana» prevalece sobre el «aprendizaje estricto para el ejercicio de una profesión». ¿Amenaza "Bolonia» de una prevalencia del aprendizaje estricto para el ejercicio de una profesión? Los resultados y las concretas planificaciones de cada "grado» y cada «área de conocimientos» lo dirán.

Seguidamente hay una referencia al interés vital estimulante del aprender: por qué aprender algo. Ahí se explica (pag 11): Es indudable que cuando [el estudiante, digamos] siente la pesadilla de contestar a 
un cuestionario [absurdo, improcedente, cabría matizar] pierde toda sospecha de que aquello que estudia tenga algo que ver con el mundo que le rodea.

¿Cómo no recordar aquí que a veces se cae en el error de enseñar, o aprender, no "para la vida»-non vitae- sino sólo para la escuela -sed scholae-? Para aprender algo (o enseñarlo) de veras hay que empezar por sentir una verdadera necesidad interior de aprenderlo, o de enseñarlo. La motivación como imprescindible y eficacísimo motor (redundancia esclarecedora) del aprendizaje. He ahí una primera función del que enseña: motivar a sus discentes. En esta idea, nuestro autor considera la inutilidad de cuestionarios que pregunten sobre cosas que el preguntado no siente necesidad alguna de saber.

Imaginemos tres círculos concéntricos: el más pequeño representa la escuela; el mediano, la profesión; el más grande -el que engloba a todos-, la vida. Optamos porque la educación sea «para la vida» en plenitud, que abarca también a "para la profesión» del modo más amplio y más versátil -o sea, más cambiante, convertibleposible.

\subsection{Enriquecer el programa, tarea esencial del profesor.}

Se dice que (pag. 13): Al maestro [entiéndase, al docente] corresponde, naturalmente, lo más interesante de la obra: la interpretación y desenvolvimiento personalísimos del programa [o, si se prefiere, de los materiales de trabajo que se utilicen en la aplicación del consiguiente programa]. [El profesor, en su caso el profesor tutor] puede enriquecer poderosamente el programa con todo aquel caudal de notas y aclaraciones de que hace un momento hablábamos.

Nos parece que se quedan cortos quienes asignan al profesor tutor, como tarea principal, la de «aclarar las dudas» que le presenten los alumnos. Los de primer curso suelen ser todavía «in-fantes», privados del habla propia de personas con cierto nivel de conocimientos: porque no tienen la más mínima certeza sobre el significado de lo que se dice en el área de conocimientos a la que acaban de asomarse.

Esperar a que nuestros alumnos de primero pregunten algo nos llevaría a admitir que lo que tienen que preguntar es todo. Debemos empezar, pues, por interpretarles y desenvolverles los contenidos de la 
asignatura que empiezan a cursar; suministrándoles las notas y aclaraciones que estimemos que necesitan. Empecemos por eso. Sus preguntas, y también sus trabajos -de algún modo creativos- han de venir después.

\subsection{Intervención: el secreto del arte de enseñar.}

Aquí está la clave (pag. 18). Todo el secreto del arte de enseñar estriba en que el alumno intervenga lo más posible en su misma educación y enseñanza, esto es, sea, autor, colaborador, no meramente receptor, oyente.

Parece como si nuestro autor supiese ya lo que iba a propugnarse en las directrices del «Espacio Europeo de Estudios Superiores» (esa «triple E» de la enseñanza universitaria en la que ahora estamos ya embarcados).

En otro lugar del libro que aquí estamos comentando se viene a decir (pag. 15) [El centro de formación, o sea, a nuestros efectos, la Universidad] pretende formar el pensamiento y juicio propios del alumno acostumbrándole a buscar y a exigir la razón de las cosas, no a aceptar éstas por la teoría de la autoridad ni de la costumbre.

Y, a renglón seguido -en esa misma página (pag.15)- se añade:

Es de la mayor trascendencia despertar el interés por la lectura [...]. El afán por leer ha de encauzarse con amplio espíritu pensando que el mejor fiscal en la distinción de los buenos y de los malos escritos es nuestro educado y sereno juicio, no la aprobación o condenación que le presten los demás.

Nuestra opinión es ésta: si, como profesores tutores de nuestras materias, conseguimos despertar en nuestros estudiantes ese irrefrenable impulso de ser, cada uno de ellos, el propio artífice de su personal aprendizaje, sin duda que habremos alcanzado el objetivo deseable. (De la juventud deseosa de [aprender] las leyes hablaba, como todos sabemos, Justiniano -«cupíditas legum», tal era su expresión-).

Nos parece también que a eso se apunta en los criterios del llamado «Plan Bolonia»: a un aprendizaje participativo, activo, creativo, y continuado en sus actividades concebidas para el aprendizaje por la práctica y para la correspondiente evaluación de tal aprendizaje. 


\subsection{Colaboración / Individualización: una contradicción sólo aparente.}

De ninguna manera se contradicen el trabajo en colaboración y la individualización del trabajo, si entendemos esta última expresión como que es preciso reconocer la autoría individualizada que corresponda a cada uno de los participantes en una tarea de carácter colectivo y en la que previamente a su realización habrá que establecer el correspondiente reparto de actividades.

Así (pag. 46): El alumno elige y desarrolla su trabajo según las materias que más le interesan y lo hace en colaboración con el grupo de compañeros que se hallen ocupados en temas análogos.

Habrá que puntualizar por nuestra parte que donde se dice materia o se dice temas podemos decir «tareas». De lo que se trata es de que los profesores tutores sepamos programar las tareas a realizar por cada alumno o por cada pequeño grupo de alumnos determinado a los efectos.

En el denominado Plan Bolonia también se fomentan las «prácticas» de aprendizaje realizadas en colaboración, propiciando el trabajo en grupo, en equipo. Se ha impuesto recientemente la expresión oficial de "grupo de investigación».

Por lo demás, cabe que el estudiante -y más en esta nuestra modalidad de enseñanza-aprendizaje a distancia o semipresencial- se administre a su gusto y de acuerdo con sus disponibilidades el tiempo dedicado al estudio de las materias de que se trate. Se dice también en el libro que comentamos (pag. 48): Ningún alumno se somete a la marcha de los demás y estudia [cada alumno] cada cosa cuando se siente con fuerzas y ánimos.

Ese es ciertamente nuestro estudiante tipo: el que prepara sus materias conforme a un plan de tiempo y espacio que, en gran medida, él mismo se marca. Sí que están nuestros estudiantes -nosotros como profesores tutores también, aunque quizás en menor grado- dentro de un planteamiento personalizado de la enseñanza / aprendizaje, tal como se propugna en las directrices del Espacio Europeo de Estudios Superiores. Eso nos parece.

\subsection{Fuentes directas: a propósito del camino a seguir para la enseñanza de historia.}

Nuestro autor afirma (pag. 36): Comienza esta educación acudiendo a las fuentes directas y atendiendo primero al acopio de materiales. 
Nos parece altamente recomendable, por no decir imprescindible, acudir al estudio de las fuentes directas, a la documentación que podemos llamar «de primera mano».

Suscribimos enteramente las palabras de La Bruyere (filósofo moralista francés de la segunda mitad del XVII) cuando dice: «El estudio de las fuentes nunca será recomendado lo suficiente; es el camino más corto, más seguro y más agradable para todo género de erudición»; y también, finalmente: "Acabad así de convenceros, mediante este método de estudio, que ha sido la pereza de los hombres la que ha estimulado a la pedantería a engrosar las bibliotecas, más que a enriquecerlas, a hacer morir el texto original bajo el peso de los comentarios; y que es ella, la pereza, la que trabaja contra sí misma y contra sus más queridos intereses, multiplicando las lecturas, las búsquedas y el trabajo que ella misma trataba de evitar. ${ }^{1}$

\subsection{Prudentia iuris.}

No hay sociedad sana posible sin derecho. El librito que nos ocupa también alude, aunque sin mayores pormenorizaciones, a un esbozo de camino para la enseñanza del derecho. Al alumno ha de advertirse -se dice- (pag. 39): La idea del Derecho entre los hombres, la necesidad del Derecho, su finalidad. [...] las nociones de justicia y de ley y el criterio de conducta que debemos seguir en vista que el derecho que cada hombre y cada cosa tiene a llenar (sic) el fin para que existen [...].

Acerca de los objetivos, métodos y tareas que cada uno de nosotros, como profesores y/o profesores tutores que somos, pueda proponerse y llevar a cabo no me resta sino, para concluir, pasar al epígrafe final de esta comunicación: es el apartado que se titula: «Quince posibles tipos de tareas a realizar entre maestros y escolares». Son los que seguidamente se dirán.

${ }^{1}$ L'étude des textes ne peut jamais être assez recommandée; c'est le chemin le plus court, le plus sûr et le plus agréable pour tout genre d'érudition. [...]. Achevez ainsi de vous convaincre par cette méthode d'étudier, que c'est la paresse des hommes qui a encouragé le pédantisme à grossir plutôt qu'à enrichir les bibliothèques, à faire périr le texte sous le poids des commentaires; et qu'elle a en cela agi contre soi-même et contre ses plus chers intérêts, en multipliant les lectures, les recherches et le travail, qu'elle cherchait à éviter. 


\section{ARS DISCENDI: 5 OPERACIONES Y 5 VALORES EN JUEGO.}

En el arte, en la técnica, de aprender deben confluir -como si enfrentásemos los dedos de una mano con los de la otra- cinco operaciones que conllevan otras tantas, cinco, actitudes o valores en juego.

Las cinco operaciones o actuaciones son: 1, Leer; 2, Entender; 3, Estructurar; 4, Recordar; 5, Expresarse (el acrónimo de este grupo de palabras es LEERÉ). Los 5 valores académicos, o actitudes, correspondientes a tales actuaciones son: 1 , Curiosidad; 2 , Criticidad; 3, Codificación; 4, Cronología; 5, Creatividad.

El Ars discendi -el Arte de enseñar- que aquí se sugiere, y cuyo desarrollo pormenorizado reservamos para otro lugar, gira en torno a los diez términos indicados. Vamos a hacer ahora una muy breve indicación sobre ellos.

\subsection{Leer. Curiosidad.}

Leer es la primera operación de quien pretende adquirir unos conocimientos. Un libro es un reservorio de información, y de experiencias, que se hace imprescindible para la transmisión de los saberes. La lectura sosegada, atenta y con criterio de un buen libro ayuda a nuestra formación y a nuestra capacitación profesional. Un buen estudiante que no sea un buen lector es algo inconcebible. No nos podemos imaginar una universidad sin libros. Ni una lección que no sea, en cierto modo, lectura; o que se base en lecturas que previamente ha realizado por su cuenta el propio profesor. La virtud, o el valor, de la Curiosidad intelectual, de estudiantes y de estudiosos, tiene su justa correspondencia en la lectura.

\subsection{Entender. Criticidad.}

Entender lo que se lee es de todo punto necesario. Leer y no entender lo que se lee es una forma de perder el tiempo.

En los cuadros de Patinir [nacido en Amberes en 1485; de cuya obra hay muestra en el Museo del Prado] se aprecia algo maravilloso: la observación minuciosa de numerosos detalles combinada con la perspectiva de grandes vistas panorámicas. Así debiera ser la lectura de un libro: que nos permita entender los detalles, mas sin perder de 
vista su contexto, su encuadramiento en un entorno amplio, de modo que podamos ver no sólo «cada árbol» sino también «el bosque» en su conjunto.

Se habla de que una buena lectura debe ser una lectura comprensiva. Sin duda que una lectura inteligente no consiste en juntar letras sino en entender lo que se nos dice mediante las palabras, las oraciones, los párrafos y parágrafos del escrito. Pero hay que ir a más: hay que entender lo que se lee y contextualizarlo, saberlo situar dentro de una unidad de mayor alcance, dentro de un todo armónico y cada vez más amplio: una lección, un bloque de temas, una asignatura, un programa de estudios.

El sentido crítico -la Criticidad - con que debemos llevar a cabo nuestras lecturas es otra condición para que éstas sean de verdadero provecho. Aceptar lo que leemos, sin pasarlo por el tamiz de nuestro propio criterio, de nuestra valoración intelectual, es hacer dejación de lo más propio del ser humano: nuestra capacidad de discernimiento.

\subsection{Estructurar. Codificación.}

Estructurar viene a ser sinónimo de organizar, de ordenar. Lo leído y entendido debe acabar estando estructurado, organizado, ordenado. ¿Cabe acaso un libro sin su índice; una ciudad sin su plano; un almacén sin su catálogo; un viaje sin su hoja de ruta, su itinerario? No son posibles. Como no es posible un vertebrado sin esqueleto. Todos los escritos de cierta extensión debieran ir precedidos de un sumario, de una sucinta designación de sus correspondientes apartados.

Información o conocimientos que no tengan su orden, su distribución lógica, su plan, su estructura, son conocimientos desparramados, desorganizados, descoordinados, frecuentemente poco útiles, fáciles de perderse. Una buena estructura primeramente ayuda al $\boldsymbol{a l}$ macenamiento de los datos; después, favorece su memorización -por la racionalidad de una buena sistemática-; y finalmente nos permite la búsqueda y recuperación de tales datos, su encuentro rápido y seguro en donde estén almacenados.

Se impone la organización de la documentación -y de los conocimientos- utilizando lo que se llama una estructura arborescente, por su semejanza con las ramas y sub-ramas de un árbol que derivan de un tronco como punto de partida. Para estructurar hay que seguir algún sistema de codificación, hay que servirse de alguna tabla de equivalencias de una serie de señales numéricas o alfanuméricas 
que permitan la designación abreviada de los distintos compartimentos de una biblioteca, de una ciencia, de un tema. Proponemos el sistema de clasificación/codificación que llamamos r-a-d-i-c-a-1²

\subsection{Retener. Cronología.}

Memorizar algo es retenerlo en el depósito de la memoria. Cuando memorizamos la lista de los Reyes godos retenemos en la memoria una lista cerrada de nombres que hemos de recordar exactamente, uno tras otro. No siempre habremos de memorizar así. Memorizar una lección, un esquema, un argumento, es cosa bien distinta de recordar al pie de la letra tal lección, tal esquema, tal argumento. En la generalidad de los casos basta con retener las ideas

${ }^{2}$ Exponemos sucintamente a continuación las características, siete en total, de lo que entendemos como sistema r-a-d-i-c-a-l de clasificación/codificación.

Primera: Radicalidad de la información. El punto de partida en la designación de un documento (o de una carpeta en la que el documento se guarde) ha de ser el correspondiente a uno de los diez sectores raíces, iniciales, identificados, cada uno, por uno de los dígitos del sistema decimal: del 0 al 9. La designación de una pieza documental se hace desde el universo de la información, desde la totalidad de los saberes, desde uno de los diez gajos, de los diez sectores radiales, en que hemos distribuido ese círculo totalizador que constituye el objeto de nuestro conocimiento.

Segunda: Alternancia de caracteres, alfabéticos y numéricos, en la denominación del documento de que se trate. Los signos alfabéticos deben emplearse alternativamente con los signos numéricos: tras un signo alfabético irá un signo numérico, y viceversa; p. ej., 58cc03roma. La alternancia de caracteres (numéricos seguidos de alfabéticos, seguidos éstos de numéricos, y así sucesivamente) potencia el reconocimiento de unos y otros y evita la confusión y la fatiga: nada destaca más junto a un número que una letra, y al revés. Designar una pieza de información con números y caracteres en alternancia, con claves alfabéticas y numéricas que se entremezclan sucediéndose es una opción que ofrece muchas posibilidades combinatorias e indudables ventajas de reconocimiento.

Tercera: Decimalización de sectores en un código de sectores primarios de información. Se parte de una determinación de exactamente diez macrosectores, hiperáreas, o grandes secciones, por así decirlo, en que queda compartimentado, sistémicamente dividido, todo el posible conocimiento humano, o su correspondiente, la información cognoscible.

Cuarta: Indizada, con indexación: las cien secciones básicas, aparte de su ordenación sistemática pueden ser indexadas alfabéticamente con remisión a sus correspondientes códigos.

Quinta: Clara, con claridad en las denominaciones: de modo que no haya expresiones ambiguas, oscuras, indeterminadas.

Sexta: Absoluta: omnicomprensiva, de manera que nada quede fuera: que cualquier asunto tenga su lugar propio.

Séptima: Legible: de modo que los signos de escritura sean inequívocos, perfectamente reconocibles; se usará, por eso, una plantilla de signos y se usarán siempre las minúsculas cuando se escriban letras. 
para después poder expresarlas con construcciones gramaticales propias, de un modo personal, flexible.

La memorización requiere comprender bien lo que se nos dice y valerse de los oportunos mecanismos de asociación, incluido el mecanismo de la rima. Sin comprender bien la información a memorizar, la retención de tal información resulta fatigosa y poco segura. Salvo excepciones, requiere un esfuerzo ímprobo, desmedido, tratar de recordar una palabra o una frase que no se ha entendido. A veces es muy útil acudir a la etimología para desentrañar el significado de una palabra que nos resulta desconocida. Una frase cuyo sentido no se haya comprendido no va a ser posible reconstruirla después. Ante un párrafo largo, o ante una serie unitaria de ellos, deberíamos saber usar la técnica de «descomponerlo» en los términos o en las ideas que en él se encierran y -con ayuda de lápiz y papel, o sólo con nuestra reflexión mental- reducirlo a algo más sencillo y breve, esencial, esquematizado, absolutamente comprensible, de muy claro significado.

Además de comprender, para memorizar hay que asociar. Hay que ver el modo de establecer un nexo de unión entre lo ya sabido y lo que estamos tratando de aprender. Y hay que saber integrar en un todo los diferentes elementos constitutivos del mismo. La imaginación y la visualización son poderosos instrumentos con que conseguir esa concatenación de ideas y conceptos tan necesaria para la evocación posterior.

Un aspecto muy concreto de la memorización consiste en saber retener fechas: situar en la escalera del tiempo ciertos acontecimientos relevantes. La memoria de la cronología requiere su técnica. Hay muchos recursos para ayudar a la memorización de fechas, pero no vamos a tratar de ellos aquí.

\subsection{Expresarse. Creatividad.}

Expresar los conocimientos adquiridos es una de las metas que debe proponerse el estudiante. «Todos sabemos lo que es el conocimiento hasta que alguien nos lo pregunta» se dijo. Esta frase nos pone de manifiesto el hecho de que si algo se sabe de verdad es que estamos en condiciones de responder adecuadamente a quien nos pregunte sobre la cuestión de que se trate: se nos pregunte sobre el conocimiento, sobre los vertebrados, sobre el usufructo o sobre la herencia pretoria. Y, en sentido contrario, nos muestra cómo si sobre determinado asunto, que creíamos saber, no sabemos contestar cuando se nos pregunta es que, de verdad, no lo sabemos. No sabemos 
nada de un asunto mientras no seamos capaces de expresarlo, de decirlo, de comunicarlo, de formularlo debidamente con palabras y frases. El saber sobre algo conlleva el saber expresarlo.

Esta expresión de lo que sabemos puede hacerse verbalmente-mediante la palabra hablada- o por escrito -mediante los signos de escritura-, pero empleando siempre la terminología adecuada. Sin los términos precisos no hay expresión lingüística posible. Cada rama del saber, cada disciplina, cada especialidad tiene su «jerga típica», su propio lenguaje, su terminología específica. Los términos con que se expresa un informático, un médico o un jurista son términos técnicos con un significado muy preciso y que hay que saber utilizar con propiedad: p. ej., compilar, osteoporosis, anticresis. Cada rama del saber tiene su terminología, su «argot».

Una exposición oral atractiva, amena, eficaz, debe estar cocinada con los ingredientes de la buena retórica, tales como: captación del interés y aun de la benevolencia del oyente, introducción al tema, desarrollo secuencial, citas apropiadas, anécdotas oportunas, conclusiones breves y claras. La redacción de un escrito no debe irle a la zaga.

En la redacción de un escrito debemos emplear con tino lo que llamaremos recursos de estética funcional: márgenes, puntos y aparte, negritas, cursivas, recuadros, tipos -y hasta tamaños- de letras, y aun, llegado el caso, colores en palabras o frases de especial significación. Nuestro trabajo debe llevar la marca de «un toque personal». Hay que poner en juego en la expresión de ideas el don de la creatividad, tanto en los contenidos como en la forma: siquiera en la forma.

\section{TRIPLE E: ESPACIO EUROPEO DE ESTUDIOS SUPERIORES}

El 28 y 29 de abril de 2009 se reunieron en Lovaina/Louvain-laNeuve, Bélgica, los ministros responsables de la educación superior en los 46 países del Proceso de Bolonia ${ }^{3}$ "para evaluar los logros de

${ }^{3}$ Proceso es término que alude a fases sucesivas de una operación. El Proceso Bolonia o Plan Bolonia tiene su origen, en el acto de la firma, por rectores de universidades europeas, de la Carta Magna de las Universidades (Magna Charta Universitatum) el 18 de septiembre de 1988, en Bolonia. Esta Carta Magna proclama principios básicos de la reforma a llevar a cabo: libertad de investigación y ensseñanza, selección de profesorado, garantía para el estudiante, intercambio entre universidades. Diez años más tarde se firmó en París la Declaración de la Sorbona: «Sorbonne Joint Declaration. Joint declaration on harmonisation of the architecture of the European higher education system by the four Ministers in charge for France, Germany, Italy and the United Kingdom. Paris, the Sorbonne, May 25 1998»; esta Declaración Con- 
dicho Proceso y establecer las prioridades para el Espacio Europeo de Educación Superior (EEES) de la próxima década».

Resultado de esta reunión fue la elaboración de un Comunicado de la Conferencia de Ministros Europeos responsables de la Educación Superior que comienza así:

«En la década que culmina en 2020, la educación superior europea contribuirá de manera fundamental a la realización de una Europa del conocimiento que sea altamente creativa e innovadora. Ante el reto de una población que envejece, Europa sólo podrá triunfar en este empeño si aprovecha al máximo el talento y la capacidad de todos sus ciudadanos y se implica plenamente en el aprendizaje a lo largo de la vida además de ampliar la participación en la enseñanza superior.»

Sigue otro párrafo, igualmente ilusionable (valga la expresión) en su planteamiento general. Su literal reproducción es lo que sigue. «La educación superior europea se enfrenta además al gran reto y oportunidades subsiguientes de la globalización y la aceleración de los desarrollos tecnológicos con nuevos proveedores, nuevos alumnos y nuevos tipos de aprendizaje. El aprendizaje centrado en el alumno y la movilidad ayudarán a los estudiantes a desarrollar las competencias que se necesitan en un mercado laboral cambiante y les facultarán para convertirse en ciudadanos activos y responsables.»

Hemos destacado lo que nos parece el objetivo de la educación superior, que esa es la idea madre del párrafo: la educación superior debe servir para el desarrollo de las competencias propias de ciudadanos [profesionalmente] activos y [humanamente] responsables. Todo ello en el contexto actual de la globalización, el desarrollo tecnológico y un mercado laboral cambiante. Y este objetivo, así como estas circunstancias, conlleva la necesaria introducción de «nuevos estilos de aprendizaje». Así consideramos lo que supone la estructura del Proyecto Bolonia.

Del planteamiento de este Proyecto se derivan, por lo que se observará leyendo los sucesivos párrafos del Comunicado de referencia, los propósitos de [*] estimular la investigación y la innovación, [*] facilitar la movilidad de los alumnos (de los estudiantes), [*] propiciar el aprendizaje permanente, a lo largo de la vida, [*] orientar la en-

junta de la Sorbona lleva la firma de los correspondientes ministros de Alemania, Francia, Italia, Reino Unido. Al año siguiente, el 19 de junio de 1999, 29 ministros de educación europeos firmaron la Declaración de Bolonia, que da el nombre al proceso y en el que se basan los fundamentos del Espacio Europeo de Educación Superior (EEES), que estará finalizado en el año 2010. 
señanza a la obtención de resultados del aprendizaje, [*] fomentar la creatividad, etc.

A excepción del propósito de facilitar la movilidad de los estudiantes (se entiende que para que puedan seguir el curso de sus estudios en cualquiera de los países del espacio europeo), todo lo demás nos parece que es connatural a la esencia misma del aprendizaje: innovador en su método, permanente en su duración, operativo en cuanto a sus resultados, creativo en cuanto a su alcance. Pero nunca está de más que se insista otra vez en lo que, por su propia naturaleza, corresponde a una verdadera enseñanza / aprendizaje que como tal se precie. Sin duda que, antes, en y después de decirlo los «gestadores» (valga la expresión) del Proyecto Bolonia, la lectura comprensiva y la correcta expresión oral o por escrito van de suyo implicados en la operación del aprender.

\section{APRENDER HACIENDO: UNA SERIE DE PRÁCTICAS POSIBLES.}

Es de todo punto aleccionador observar cómo, en algún reportaje televisivo visto sobre el mundo de lo animales llamados irracionales, una nutria enseña a sus hijos a fabricarse su madriguera: les enseña haciendo, como no podría ser de otra manera pues ahí no hay lección teórica posible.

Un estudiante también debe aprender haciendo [lo que supone en muchas ocasiones aprender viendo lo que otro hace]: es el modo de aprender más personalizado y efectivo. Salvando siempre cualquier otro criterio, nuestra propuesta de actividades formativas que podrían realizar los estudiantes, con la muestra, orientación, coordinación, supervisión y valoración del profesor correspondiente, es la que se concreta en los términos, por orden alfabético, que siguen. 1: Antología. 2: Bibliografía. 3: Cronología. 4: Documentos. 5: Encuestas. 6: Fuentes. 7: Geografía. 8: Historia. 9: Iconografía. 10: Máximas. 11: Noticiario. 12: Personajes. 13: Quaestiones. 14: Redacción. 15: Síntesis. 16: Tests. 17: Vocabulario.

\subsection{Antología.}

Antología. Elaboración de una selección, y su oportuna transcripción, de textos de autores referentes a determinado tema. Se trata de una colección ordenada, sistematizada, y aun con su comentario crí- 
tico, global o pormenorizado, de los escritos de que se trate. La transcripción de un texto, si el que transcribe sabe poner inteligentemente en juego los diversos recursos tipográficos con que hoy se cuenta (subrayados, negritas, cursivas, etc.), ya puede resultar algo creativo que nos dé muestras del nivel de la capacidad intelectual de quien ha realizado tal tarea. La aportación todavía más personal de una antología de textos será sin duda la sistematización y comentarios que de ellos se haga.

\subsection{Bibliografía.}

Bibliografía. Repertorios, reseñas y recensiones de todo tipo de escritos doctrinales: todo eso cabe bajo el enunciado de Bibliografía. El estudiante que realice un trabajo de esta naturaleza enriquecerá sus conocimientos, conectará saberes, estimulará su capacidad de síntesis y ejercitará sus dotes de selección y desarrollará el buen sentido de la crítica intelectual, del juicioso discernimiento.

\subsection{Cronología.}

Cronología. Una relación mínima, pero esencial, de hechos relevantes siguiendo un orden cronológico. Como primera medida, sería imprescindible la cronología minimalista de una fecha por siglo: quedarían fijados de ese modo los hitos más someros en torno a los que poder insertar después otros acontecimientos dentro de su contexto temporal.

\subsection{Documentos.}

Documentos. Materiales que se aportan para la composición de contenidos. Lo que más a mano suele tener un estudiante, pero no debe limitarse a hacer eso, es bajar de la Red algún tipo de documentación más o menos relacionada con el asunto sobre el que se le encarga un trabajo. A veces es penoso lo que algún alumno nos presenta como trabajo personal: meras descargas de documentos, pasados naturalmente por la impresora, sin aportación alguna: ni una reelaboración sistemática, ni un comentario crítico, ni el más mínimo retoque formal; como quien caza un corzo por azar y nos lo deja a la puerta de nuestra casa para que hagamos con él lo que nos plazca: desollarlo y cocinar su carne, o acaso quedarnos con la piel y encar- 
gar que la curtan. Sin embargo la recogida y selección de documentos puede ser un magnífico primer paso para, sobre su almacenamiento, llevar a cabo después las tareas de análisis y sistematización que pueden dar lugar a una redacción personal, creativa, original y, desde luego, documentada.

\subsection{Encuestas.}

Encuestas. Más allá de las que sirvan para que los propios estudiantes evalúen la competencia y la actividad de sus profesores, cierto tipo de encuestas pueden decirnos algo sobre el equipamiento y destrezas de los estudiantes. En la encuesta que en diciembre de 2010 se aplicó a los estudiantes de Fundamentos Clásicos de la Democracia y de la Administración (en concepto de «Evaluación Actividad Tutorial. Asignaturas de Grados», dentro del llamado Plan Bolonia) del total de 16 preguntas sólo una, la 16, hace referencia directa al estudiante. Está redactada en estos términos: «Indique el tiempo medio semanal dedicado al estudio de esta asignatura». Las alternativas de respuesta son: «1, menos de 1 hora; 2 , entre 1 y $5 ; 3$, entre 5 y 10; 4, más de 10 horas; 5 sólo estudio antes de los exámenes; 6 , no contesta». Nos parece que sería de mucho interés para el profesor, a fin de poder planificar mejor las actividades durante el curso, un conocimiento previo, mediante encuesta, de algunas características del alumnado, tales como, por ejemplo, grado de alfabetización informática, equipamiento electrónico a su alcance, perfil de la biblioteca de su uso, etc.

\subsection{Fuentes.}

Fuentes. Textos que constituyen fuentes directas de conocimiento. Pasajes de fuentes documentales: reproducción y/o comentarios. Se incluirán aquí, por ejemplo, el Digesto de Justiniano, la Constitución Española, el Código civil, etc. La construcción de selecto corpus de fuentes directas, realizado con la participación de diferentes, y hasta sucesivos, grupos de estudiantes, puede plantearse como uno de los más brillantes y útiles objetivos de la tarea académica. Supone esta tarea cierto grado de creatividad de quienes participen en la misma y también se consigue con ello la provisión de unos insustituibles materiales de trabajo de permanente uso. 


\subsection{Geografía.}

Geografía (el dónde: espacio). Mapas de lugares en que ocurrieron los acontecimientos. Es preciso que ciertos acontecimientos significativos tengan su concreta referencia al lugar en que se produjeron. Esta referencia se hace necesaria para un cabal aprendizaje. La actividad de poner sitio a lo ocurrido es tarea en la que muy bien cabe la activa participación de quien se está formando.

\subsection{Historia.}

Historia (el cuándo: tiempo). Secuencia de acontecimientos notables, siguiendo un orden cronológico. Esta Historia es de más amplio alcance que la ya mencionada «cronología», minimalista. Podemos plantearnos una historia general en la que quepan todo tipo de acontecimientos. También podemos hacer una historia más específica, una historia sectorial, pues, al filo de la sucesión en el tiempo, se pueden estructurar determinados conocimientos específicos, que variarán según el modelo de historia sectorial elegido: por ejemplo, sobre evolución del proceso, sobre las diferentes concepciones del derecho, sobre el régimen jurídico de la sucesión mortis causa, etc. La historia no es una simple relación de hechos, sino un desarrollo de los conocimientos sobre tales hechos. Pero sí requiere, la historia, una cierta secuencialización de los hechos: la estructura secuencial es requisito imprescindible de la sucesión de acontecimientos a que la historia hace referencia.

\subsection{Iconos.}

Iconos. Representaciones gráficas: pinturas, esculturas, imágenes. El hilo conductor de una serie de iconos puede ser la historia, su sucesión en el tiempo; o también se pueden exponer conforme lo requiera la propia secuencia temática. En todo caso, nos parece inevitable la elaboración de un índice cronológico de las representaciones gráficas en juego: así quedarán ubicadas en el momento del suceso a que hacen referencia y mantendrán entre sí su indiscutible orden en el tiempo.

\subsection{Máximas.}

Máximas. Máximas, sentencias, citas, frases célebres. Según los personales intereses o aun conforme a un previo plan a ejecutar en 
grupo, cabe el ejercicio de recopilación de una serie de expresiones que interese recordar o comprender. El orden de exposición puede ser sistemático, con un índice alfabético complementario, o simplemente alfabético.

\subsection{Noticiario.}

Noticiario. La historia es un pasado recurrente, no muerto del todo, que se reaviva con motivo de alguna noticia. Pensemos, por ejemplo, en estos acontecimientos actuales: «Atenas celebra los 2.500 años de la Maratón. Miles de aficionados emularán la histórica carrera emblema de los Juegos Olímpicos» (un titular publicado en el diario El Mundo, sábado 30 de octubre de 2010). «Nuria Espert. La violación de Lucrecia. William Shakespeare» (anuncio de la cartelera del Teatro Español, diciembre 2010). «Exposición sobre Alejandro Magno» (anunciada en la prensa, enero 2010). Otra noticia de prensa (en el diario La Razón, miércoles 19 de enero de 2011): «Calígula recupera su villa olvidada. El saqueo de una escultura saca a la luz la mítica villa que construyó el emperador romano». Se prestan estas noticias a tomarlas como el hilo del que sacar el ovillo de qué pasó entonces, cuál fue el significado de tal hecho, de tal personaje, cuáles eran las circunstancias históricas y culturales de aquel tiempo, etc.

\subsection{Personajes.}

Personajes (el quién). Biografía de personajes destacados -su historia personal-Puede referirse a un emperador, a un jurista, a un filósofo, a cualquier tipo de personaje con cierta significación histórica. No se trata sólo de una fría referencia de fechas relacionadas con la figura histórica en cuestión, sino de explicar su obra y el contexto histórico en que se produce, con sus antecedentes y sus consecuentes y, si cabe, su grado de actualidad.

\subsection{Quaestiones.}

Quaestiones. Preguntas sobre asuntos a las que hay que dar respuesta breve razonada. En la resolución de un caso práctico conviene a veces formular preguntas puntuales: así, por ejemplo, qué obligaciones tiene tal sujeto como usufructuario frente a tal otro como nudo propietario, o si procede tal acción procesal y por qué. 
Entendemos este tipo de preguntas, que para evitar confusiones podemos llamar con la expresión latina de «Quaestiones», como algo que (a) no se queda en la simplicidad de la pregunta que se responde mediante selección de una de las opciones de respuesta ya fijadas (prueba llamada «tipo test»), pero que (b) tampoco llega a ser la redacción de un informe a campo abierto sobre el caso o asunto del que quien pregunta sólo da el enunciado.

\subsection{Redacción.}

Redacción. Trabajos de redacción, de expresión por escrito, sobre un tema de cierta amplitud. Aquí se han de poner de manifiesto lo que podemos llamar las siete virtudes de un escrito. Tres son sobre la forma: [1] Entendibilidad (lo ininteligible, por ilegible, es incorregible: la claridad gráfica es lo primero), [2] Estructura (todo escrito debe tener su propia estructura, debe seguir un orden), [3] Estética funcional (con los indicadores tipográficos en uso se procurará lograr una cierta estética funcional). Y cuatro son (aunque el fondo y la forma son en verdad inseparables) sobre el contenido, el fondo: [4] Secuencialidad, (la redacción debe ser fluida, secuencial, con ilación expositiva), [5] Sintaxis (frases con sintaxis correcta, sin anacolutos), [6] Síntesis (ajustándose al tema, ciñéndose al asunto: sin divagaciones), [7] Terminología: vocabulario (cada asunto requiere el uso de su propio vocabulario técnico).

\subsection{Síntesis.}

Síntesis. Esquemas y resúmenes de alguno de los contenidos del programa. Una síntesis es algo más que un mero esquema; pero menos que un resumen amplio. La síntesis dice lo esencial del tema. En colaboración, distribuyendo tareas, se puede conseguir un amplio y solvente repertorio de síntesis de los temas de un curso, que valga como "prontuario", como elemento de repaso, de consulta, de base en que apoyarse para conocimientos o investigaciones posteriores

\subsection{Tests.}

Tests. Preguntas. Repertorio de ítems para tests. Preguntas objetivas, modalidades: de selección de alternativa de respuesta; de asociación; de complementación; etc. Ya se sabe que no es fácil elaborar 
una buena batería de preguntas objetivas. Ya se sabe que el trabajo de corrección es sencillo. Ya se sabe que los tests como prueba única no es lo recomendable.

\subsection{Vocabulario.}

Vocabulario. Voces (el qué). Diccionario de términos con explicación de su significado: glosario. En el vocabulario ideal que se propone como práctica no debiera faltar, en lo posible, una referencia al sentido verdadero de la palabra de que se trate, a su origen: es una buena manera de entender en profundidad su sentido. Se puede construir un repertorio de voces como cuerpo único. Pero también se puede estructurar un repertorio de voces por sectores, por ejemplo, como sucesivos complementos de lo que en los capítulos de un libro se diga en el texto: de ese modo la explicación, asociada al texto que necesita ser explicado, resultaría más práctica y sencilla de consultar; lo que no impide que se haga además un índice general de enunciado de voces con referencia al grupo en que tales voces se explican.

Todas estas series de actividades pueden ser aplicadas tanto en la enseñanza de concurrencia física como en la de concurrencia virtual (de presencia entre ausentes, o sea, remota), ya que lo que cuenta no es la inmediatez de un tiempo y un espacio físico que el profesor y el estudiante comparten (que es lo que caracterizó hasta ahora la enseñanza de concurrencia en el aula) sino la actividad a realizar y su logro (lo que bien se puede llevar a cabo mediante la ocasional concurrencia en el espacio virtual de los actores de una comunicación recíproca, o sea, de ida y vuelta).

Por otra parte, las actividades cuya práctica se propone no deben entenderse como compartimentos estancos. Cabe, por ejemplo, que un trabajo de redacción incorpore sus pertinentes iconos, su síntesis, etc. Y lo mismo cabe que una selección y reproducción de documentos incorpore un complemento de cronología o de voces. La tarea de más generalizado uso quizá sea la de redacción. Pero la redacción puede resentirse en cuanto a la creatividad (si se propone un limitado repertorio de temas, que inevitablemente dará lugar a «repeticiones» en su desarrollo).

Optamos por un más amplio repertorio de prácticas, por algo más que trabajos de redacción sobre temas prefijados. Optamos por que los propios alumnos, individualmente o en grupos, puedan proponer los concretos trabajos que deseen llevar a cabo, y que serán de- 
bidamente orientados y evaluados después por su profesor. Optamos por la confección de materiales útiles no sólo para el que los elabora sino también, si cabe, para otros estudiantes. Más que a un mero "cuaderno de prácticas», las tareas a realizar en la propia formación debieran de conducirnos a un «cuaderno práctico», práctico para quienes lo elaboran y práctico para quienes lo puedan después utilizar: ésa es la enseñanza participativa y cooperativa que suscribimos.

Todo en pos del logro de una mejor formación teórico-práctica de los estudiantes que, por imperativos sociales y tecnológicos van dejando atrás la faceta de "homo audiens» y se van cada vez más incorporando a la dimensión de «homo ludens», sin pasarse, que la ludopatía es un vicio, y, lo que es de todo punto deseable al «homo agens»; y, Dios lo quiera, a la profunda dimensión humana y científica de «homo prudens» o aun de «homo iuridicus prudens».

\section{CONCLUSIONES}

\subsection{Primera conclusión:}

La enseñanza-aprendizaje orientada a la capacitación técnico-profesional.

Lo que, a nuestro juicio, se pretende con la constitución de este Espacio Europeo es, primordialmente, que el estudiante llegue a alcanzar la capacitación técnica, la habilitación técnico-profesional, acorde con las necesidades de mercado de la sociedad actual: una sociedad global, competitiva y dominada por las tecnologías de la información y de la comunicación.

Creemos que, más allá, o más acá, de la capacitación profesional (o sea, del desarrollo -sic- de las competencias), la enseñanza-aprendizaje debe no perder de vista la razón de ser de una verdadera formación humana -curiosidad intelectual, sentido crítico, sensibilidad humana, valores morales, etc.- sobre la que la propia capacitación técnica de cualquier persona debiera asentarse.

\subsection{Segunda conclusión:}

La metodología de la enseñanza no es ajena a experiencias anteriores. 
Innovar de verdad no es tarea fácil. Sin embargo es sencillo presentar como nuevo lo que sólo es de nombre. Algunas supuestas novedades tienen sus precedentes. En el Proyecto Bolonia, que lleva un título-marca prestigioso, se asimilan, por suerte, buenas dosis de experiencias acumuladas del pasado: de la enseñanza-aprendizaje de lo que fue y sigue siendo la Universidad de Bolonia, y, más recientemente, de lo que aportó a la escuela la española Institución Libre de Enseñanza.

\subsection{Tercera conclusión}

La realidad de nuevas herramientas y nuevos recursos para el aprendizaje

Hemos pasado de la máquina de escribir a los ordenadores; y de la prensa escrita y las bibliotecas al correo electrónico y a los blogs, las bitácoras en Internet. La enseñanza, y la investigación, no pueden prescindir de las nuevas herramientas de trabajo que proporciona la informática, la comunicación electrónica, la documentación alojada en bancos de datos y en una extensa red de bibliotecas virtuales.

El aprendizaje no puede reducirse a la asimilación de conocimientos, sino que debe incluir el adiestramiento [a] en el manejo de las nuevas herramientas de trabajo y [b] en la utilización de los nuevos recursos de información, de los nuevos tipos de documentos.

Se ha venido a decir, con acierto, que un adecuado adiestramiento en el manejo de las Tecnologías de la Información y de la Comunicación (las TIC) permite [a profesores y estudiantes] [1] utilizar foros asincrónicos (a modo de tablón de anuncios puestos en el espacio virtual) y de comunicación directa (una comunicación telemática en tiempo real, lo que en inglés se llama un «chat»), [2] descargar documentos, bajarse de la red de computadores, de internet, todo tipo de documentos (los documentos «de apoyo»-como complemento o ayuda a la enseñanza-, los repertorios bibliográficos, los enunciados de actividades a realizar, etc.), [3] subir documentos a internet (es decir, enviarlos a la dirección electrónica que proceda, colgarlos para que lleguen a su/s destinatario/s), [4] usar bases de datos (es decir, reservorios estructurados de piezas de información) $)^{4}$.

\footnotetext{
${ }^{4}$ Vid.: Uned. Grado en Derecho. Curso 2010-2011. Guía de estudio de la asignatura «Derecho Romano», 2 ${ }^{\mathrm{a}}$ parte: Plan de trabajo y orientaciones para su desarrollo, pag. 14 [dentro del apartado 3.1. Orientaciones para la realización del plan de actividades].
} 


\subsection{Cuarta conclusión}

Las actividades a realizar por el estudiante son pieza esencial para su formación

En términos generales, la actividad tradicional del estudiante consistía en estudiar, en aprender unos conocimientos. Con el planteamiento de la enseñanza universitaria como un desarrollo (o adquición) de habilidades, cambian los objetivos: no basta con saber, sino que es preciso saber hacer. Y la tarea del estudiante cambia, se desplaza: de [a] un compartamiento receptor, pasivo, memorizador, pudiera decirse en algún caso, se pasa a [b] un comportamiento activo, creativo de algún modo ${ }^{5}$.

\subsection{Quinta conclusión}

Un dirigismo que se contrarresta con cierta permisividad.

El dirigismo - es decir, la intervención abusiva en una actividad por parte de quien la dirige- supone una limitación a la iniciativa, la libertad, la creatividad del dirigido. En algún caso el dirigismo queda bastante rebajado si se da opción de cumplir lo establecido como norma o de no cumplirlo del todo. Es la contradición que puede observarse en algún plan de estudios.

\section{BIBLIOGRAFÍA DE REFERENCIA}

\section{Material impreso}

ALEGRE, L. y MORENO, V. -coords.- (2009), Bolonia no existe. La destrucción de la Universidad europea (Hiru)

${ }^{5}$ Las habilidades (competencias para un quehacer profesional, capacitaciones para el mercado laboral) aluden precisamente a la «tenencia» (habilidad viene del verbo latino habére, que quiere decir, "tener») de la capacidad para hacer algo: el Diccionario de la Real Academia define habilidad como detreza en ejecutar algo. Sinónimo de habilidad es destreza (habilidad para hacer algo), término que significa experto en el manejo, en la utilización, con la mano derecha, con la diestra, de la espada o las armas. En fin, que en la formación del estudiante, si se trata de aprender a hacer, importa mucho la realización de tareas concretas, actividades bien diferentes de la mera retención de ciertos saberes que «se dicen». La capacitación profesional requiere estar preparado respecto a ciertas tareas que «se hacen». 
CRESPO HERRERO, Juan José (1880), Renacimiento de la ciencia del derecho en el siglo XII, (Tipografía de Gregorio Estrada)

FERNÁNDEZ LIRIA, C. y SERRANO GARCÍA, C. (2009): El plan Bolonia (Ed. Catarata)

RUÉ DOMINGO, Joan (2007). Enseñar en la Universidad. El EEES como reto para la Educación Superior (Narcea)

SÁINZ, Fernando (1927), El programa escolar. (Publicaciones de la Revista de Pedagogía)

\section{Sitios en la Red}

www.cienciaspuras.com/opciones_universidad.htm www.uned.es

http//es.wikipedia.org/wiki/Proceso_de_Bolonia 
